\title{
Calcium-dependent signalling in B-cell lymphomas
}

\author{
Fedor Berditchevski $\mathbb{D}^{1 凶}$, Eanna Fennell (iD $)^{2}$ and Paul G. Murray $\left(\mathbb{D}^{2,3 凶}\right.$
}

(C) The Author(s) 2021

Induced waves of calcium fluxes initiate multiple signalling pathways that play an important role in the differentiation and maturation of B-cells. Finely tuned transient $\mathrm{Ca}^{+2}$ fluxes from the endoplasmic reticulum in response to $\mathrm{B}$-cell receptor (BCR) or chemokine receptor activation are followed by more sustained calcium influxes from the extracellular environment and contribute to the mechanisms responsible for the proliferation of B-cells, their migration within lymphoid organs and their differentiation. Dysregulation of these well-balanced mechanisms in B-cell lymphomas results in uncontrolled cell proliferation and resistance to apoptosis. Consequently, several cytotoxic drugs (and anti-proliferative compounds) used in standard chemotherapy regimens for the treatment of people with lymphoma target calcium-dependent pathways. Furthermore, 10\% of lymphoma associated mutations are found in genes with functions in calcium-dependent signalling, including those affecting B-cell receptor signalling pathways. In this review, we provide an overview of the $\mathrm{Ca}^{2+}$-dependent signalling network and outline the contribution of its key components to B cell lymphomagenesis. We also consider how the oncogenic Epstein-Barr virus, which is causally linked to the pathogenesis of a number of B-cell lymphomas, can modify $\mathrm{Ca}^{2+}$-dependent signalling.

Oncogene (2021) 40:6321-6328; https://doi.org/10.1038/s41388-021-02025-8

\section{MATURE B-CELL DIFFERENTIATION}

Around $90 \%$ of all B-cell neoplasms are derived from mature B cells [1], i.e., cells that have undergone rearrangement of their immunoglobulin (Ig) heavy chain and light chain genes in the bone marrow, express surface B-cell receptor (BCR) and have been selected against autoreactivity. The mature B-cells that emerge from the bone marrow are known as naive $B$ cells. These cells coexpress the $\mathrm{BCR}$ as $\lg \mathrm{M}$ and $\lg \mathrm{D}$ molecules and will become activated if their $B C R$ recognises its cognate antigen. Thereafter, the antigen-activated $B$ cells migrate into $B$ cell follicles and establish a germinal centre (GC). In the GC, the B-cells proliferate and activate several key processes that include somatic hypermutation (SHM), which introduces mutations in the lg heavy and light chain variable region genes to improve the affinity of the $B C R$, and class switch recombination (CSR) in which the isotype of the Ig heavy chain is changed to either $\lg G, \lg A$, or $\lg E$ [2]. Only a fraction of antigen-specific $B$ cells survive the $G C$ reaction and emerge as either plasma cells or memory B cells. Most B-cell lymphomas arise from cells that have been through a GC reaction, reflecting the increased risk of mutation in cells undergoing SHM and CSR.

\section{ACTIVATION OF $\mathrm{CA}^{2+}$-DEPENDENT SIGNALLING PATHWAYS IN B CELLS}

Changes in the intracellular calcium concentration in B cells are tightly controlled by coordinated signals initiated by cell-surface receptors (e.g., BCR, chemokine receptors) and by various calcium channels and antiporters.

Signalling via the $B C R$. Initiation of calcium-dependent signalling has best been characterised in the context of BCR activation. The binding of antigen to the BCR results in activation of the associated cytoplasmic tyrosine kinases (Syk and Btk), that, in turn, phosphorylate and activate phospholipase $C$ gamma 2 (PLC 2 2). PLC 2 generates inositol trisphosphate (IP3) that binds to the IP3 receptors (IP3R) and induces the first wave of $\mathrm{Ca}^{2+}$ influx to the cytoplasm from the endoplasmic reticulum (ER). Calcium depletion from the ER stores is sensed by the ER-associated stromal interaction molecule 1 (STIM1), that is translocated to the junction between the ER and plasma membrane and activates calcium release-activated channels (CRAC) - Orai1/2. This leads to the second wave of calcium influx to the cytoplasm and subsequent repletion of the ER stores. Several cell surface molecules control the BCR-induced calcium signalling in B cells [3]. For example, activation of Btk, an upstream regulator of PLC 2 , is also controlled by CD19-associated phosphatidylinositol-triskinase (PI3K), that facilitates the recruitment of Btk to the plasma membrane [4]. By contrast, BCR-induced phosphorylation of inhibitory Fc-receptors (FcyRIIB) and CD22, a member of the Siglec family of sialic acid receptors, recruit SHP-1 tyrosine phosphatase, that negatively regulates the upstream activators of PLCY2 [5].

Signalling via GPCRs. Several chemokines and bioactive lipids, acting through G-protein-coupled receptors (GPCRs), control calcium waves in B cells [6]. Activation of GPCRs can either feed into BCRinduced $\mathrm{Ca}^{2+}$ fluxes via the Btk-PLCY2 signalling axis [7] or via Gprotein-associated PLC $\beta$ s [8]. GPCRs can also act directly on the IP3R by activating cyclic AMP-dependent protein kinase A [9].

Calcium channels in signalling. In addition to CRAC-Orai-STIM complexes, B cells express non-store-operated calcium channels [10]. While their role in $\mathrm{Ca}^{2+}$-dependent signalling pathways and

\footnotetext{
${ }^{1}$ Institute of Cancer and Genomic Sciences, The University of Birmingham, Edgbaston, Birmingham B15 2TT, UK. ${ }^{2}$ Health Research Institute, University of Limerick, Castletroy, Limerick V94 T9PX, Ireland. ${ }^{3}$ Institute of Immunology and Immunotherapy, University of Birmingham, Birmingham B15 2 TT, UK. ${ }^{凶}$ email: f.berditchevski@bham. ac.uk; P.G.Murray@bham.ac.uk
} 
in the differentiation of mammalian B-cells remains largely unknown, experiments involving the avian B-cell line (DT40) demonstrated that TRPC3 and TRPC7, two diacylglycerol-activated TRP channels, may contribute to BCR-induced influx of extracellular calcium [11].

\section{ORIGIN OF MATURE B-CELL LYMPHOMAS}

The classification of the mature B-cell lymphomas into distinct entities is partly based on similarity to their normal B-cell counterparts and assumes that the malignant cells retain many characteristics of the normal cells. For example, Burkitt lymphoma (BL) expresses markers that are characteristic of normal germinal centre B-cells (e.g., BCL6 and CD10) [12]. Chronic lymphocytic leukaemia and small lymphocytic lymphoma (CLL/SLL) are characterized by the clonal expansion of $\mathrm{CD} 5+\mathrm{B}$ cells. In many cases, the transformed cells remain dependent on the expression of a functional BCR; such tumours include $B L$, diffuse large B-cell lymphoma (DLBCL), mantle-cell lymphoma (MCL), CLL/SLL and marginal zone lymphoma (MZL). In some cases, there is evidence of aberrant BCR signalling driven in part by genetic alterations. For example, the two major 'cell of origin' subtypes of DLBCL, known as the activated B-cell (ABC) and germinal centre B-cell (GCB) forms, show strikingly different mechanisms of aberrant $B$-cell receptor (BCR) activation. In $A B C-D L B C L$, so-called chronic active $B C R$ signalling activates both the nuclear factor-KB (NF-KB) and $\mathrm{PI}$ KK/AKT pathways [13]. This is a consequence of BCR cross-linking induced by self-antigens expressed on the same or adjacent cells, combined with sustained signalling resulting from pathway mutations, for example in CD79B [14]. In contrast, only the PI3K/ AKT pathway is activated downstream of the BCR in GCB-DLBCL and signalling is antigen-independent and referred to as 'tonic' $[15,16]$. The degree of mutation of the genes encoding the immunoglobulin heavy chain clonotype of the BCR is among the most robust prognostic tools for CLL/SLL, dividing patients with 'unmutated' CLL (U-CLL) as having more aggressive disease outcomes, or so-called 'mutated' CLL (M-CLL) as having more indolent disease course [17]. On the other hand, some mature B-cell lymphomas, for example, classical Hodgkin lymphoma ( $\mathrm{cHL}$ ) and primary mediastinal $B$ cell lymphoma (PMBCL), are characterised by the loss of BCR functions. This can be a consequence of either so called 'crippling' mutations in the immunoglobulincoding genes, epigenetic silencing of key BCR components or their transcriptional down-regulation, for example, by the EpsteinBarr virus (EBV)-encoded latent membrane proteins- 1 and $2 \mathrm{~A}$ [18-20].

While in BCR-expressing lymphomas receptor crosslinking is likely to provide the most powerful and sustained signal leading to activation of $\mathrm{Ca}^{2+}$-dependent pathways, engagement of several other surface receptors also feeds into calcium haemostasis. Lectin binding to DC-SIGN induces persistent activation of PLCY2 in follicular lymphoma cells [21]. Activation of CXCR4 in DLBCL cells induces both transient (PLC-dependent) and sustained (STIMORAl-1-dependent) calcium influx [22]. Binding of Wnt5 to its Frizzled-5 receptor-induced $\mathrm{Ca}^{2+}$-dependent activation of NFAT and NF-KB in BL cells [23]. In BCR-independent lymphomas, calcium homeostasis is regulated by a number of other surface receptors. For example, ligation of the CD30 receptor expressed on malignant cells induces $\mathrm{Ca}^{2+}$ influx in $\mathrm{CHL}$ [24]. Similarly, stimulation of cysteinyl leukotrienes receptors (CysLTR1) induces strong calcium signalling in the malignant cells of both $\mathrm{CHL}$ and PMBCL $[25,26]$.

\section{CALCIUM-BINDING ENZYMES IN B-CELL LYMPHOMAS}

There are hundreds of calcium-binding proteins in cells whose activity could be affected by induced $\mathrm{Ca}^{2+}$ waves in $\mathrm{B}$ cells. Genetic profiling of $B$ cell lymphomas has identified that a

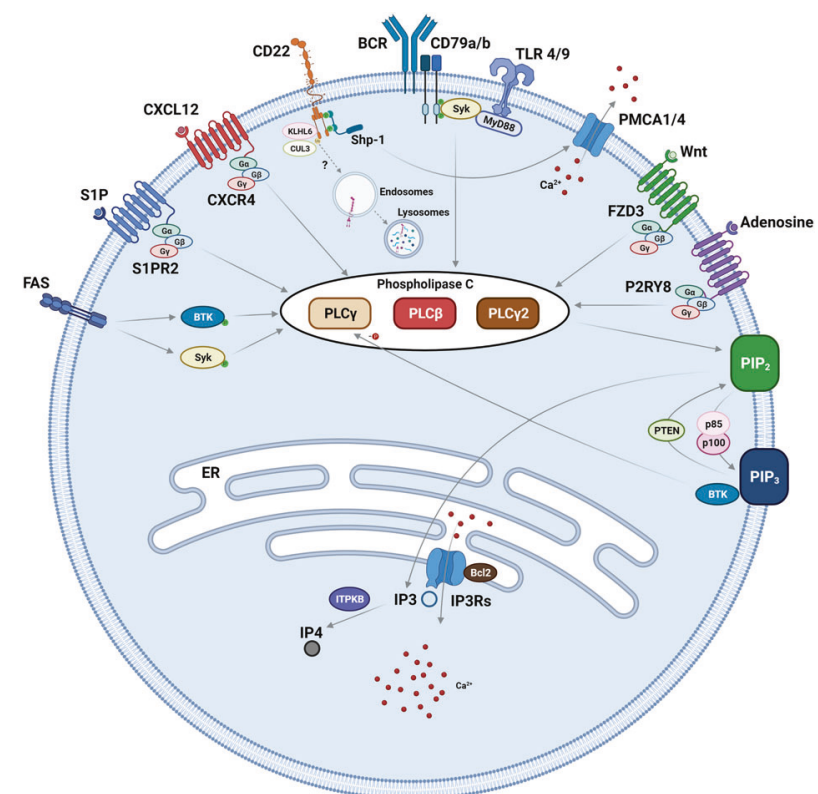

Fig. 1 Major $\mathrm{Ca}^{2+}$-dependent pathways that could be affected by genes mutated in B-cell lymphomas (Table 1). Activation of surface BCR complex (i.e., membrane immunoglobulin $(\mathrm{mlg}$ ) associated with covalently linked CD79a-CD79b heterodimer) and other surface receptors (e.g., TLRs, CXCR4, and FAS) by their ligands results in PLCdependent hydrolysis of phosphatidylinositol bisphosphate (PIP2) and generation of inositol triphosphate (IP3). PLCs are activated either by Syk and Btk tyrosine kinases which induced tyrosine phosphorylation of the protein (e.g., PLC $\gamma 2$ ) or via binding to $G \beta \gamma$ subunits of trimeric GTP-binding proteins $(P L C \beta)$ that are coupled to cell surface receptors (CXCR4, FZD3, P2RY8, and S1PR2). IP3-bound receptors (IP3Rs) on the endoplasmic reticulum (ER) induce release $\mathrm{Ca}^{2+}$ from the ER leading to activation of various cytoplasmic enzymes (Fig. 2). CD22 forms a tripartite complex with protein tyrosine phosphatase non-receptor type-6 (Shp-1) and plasma membrane $\mathrm{Ca}^{2+}$-ATPase (PMCA) that regulates $\mathrm{Ca}^{2+}$ efflux pathway. Kelch-like protein 6 (KLHL6) functions as an adaptor for Cullin-3 (CUL3), an E3 ubiquitin ligase that regulates internalisation (and possibly degradation) of CD22 thus negatively affecting the contribution of the protein to calcium homeostasis. Phosphoinositide 3-kinases (PI3Ks, p85/p100) and Phosphatidylinositol 3,4,5trisphosphate 3-phosphatase (PTEN) control interconversion of PIP2 and phosphatidylinositol trisphosphate (PIP3) on the plasma membrane. Binding to PIP3 enhances enzymatic activity of Btk resulting in increased Btk-dependent phosphorylation of PLC $\gamma$.

significant proportion of mutations occur in genes with functions in calcium-dependent signalling (Fig. 1, Table 1). Importantly, some of the reported mutations have been shown to enhance calcium-dependent homeostasis in model lymphoma cell lines $[27,28]$. Here, we will only discuss $\mathrm{Ca}^{2+}$-dependent enzymes with established links to B-cell lymphomagenesis.

\section{PROTEIN KINASE C (PKC) ENZYMES}

The family of PKC is composed of 9 isoforms including a subgroup of $\mathrm{Ca}^{2+}$-dependent enzymes: PKCa, PKC $\beta \mathrm{I} / \mathrm{II}$, and PKC $\mathrm{P}$. While PKC $\gamma$ is not expressed in B-cells, both PKCa and PKC $\beta$ have been shown to play important roles in B-cell differentiation [29]. Although the proliferation of B cells was not affected in PKCa-deficient mice, there was diminished antigen-specific $\lg M$ to $\lg G 2 a$ and $\lg G 2 b$ switch in these animals [30]. Experiments involving PKC $\beta$-knockout and PKC $\beta$-transgenic animals have revealed a signalling link between BCR-dependent activation of Btk and PKC $\beta$ [31-33]. An early study using PKC $\beta$-knockout mice demonstrated that although $B C R$-induced signalling is suppressed in these 
Table 1. Frequencies of mutations in genes involved in $\mathrm{Ca}^{2+}$-dependent signalling in B-cell lymphomas.

\begin{tabular}{|c|c|c|c|c|c|c|c|c|}
\hline GENE & Protein & CLL/SLL & DLBCL & MCL & $\mathbf{F L}$ & BL & MZCL & CHL \\
\hline BTK & BTK, Bruton Tyrosine Kinase & 4.0 & 1.6 & 4.2 & 1.2 & - & 1.0 & - \\
\hline CD79A & B-Cell Antigen Receptor Complex-Associated Protein alpha Chain & 0.2 & 2.8 & - & 1.2 & - & 0.5 & 4.8 \\
\hline CD79B & B-Cell Antigen Receptor Complex-Associated Protein beta Chain & 0.3 & 9.6 & - & 1.4 & 4.7 & 1.8 & 1.3 \\
\hline CXCR4 & C-X-C Motif Chemokine Receptor 4 & 1.4 & 2.3 & - & 2.2 & 9.7 & 3.5 & - \\
\hline FAS & Fas Cell Surface Death Receptor & 0.4 & 6.2 & 4.9 & 12.5 & - & 22.8 & 1.3 \\
\hline S1PR2 & S1PR2, Sphingosine-1-Phosphate Receptor 2 & 0.7 & 4.0 & - & - & 8.8 & - & - \\
\hline ITPR2 & Inositol 1,4,5-Trisphosphate Receptor Type 2 & 2.8 & 2.2 & 9.1 & 3.6 & 0.5 & - & 3.8 \\
\hline ITPR3 & Inositol 1,4,5-Trisphosphate Receptor Type 3 & 0.5 & 1.4 & - & 3.6 & - & - & 3.8 \\
\hline ITPKB & Inositol-Trisphosphate 3-Kinase B & 1.7 & 5.4 & 2.4 & 1.8 & - & - & 13.9 \\
\hline FZD3 & FZD3, Frizzled Class Receptor 3 & 0.6 & 0.3 & - & 1.8 & 9.3 & 4.0 & - \\
\hline P2RY8 & Purinergic Receptor $\mathrm{P} 2 \mathrm{Y} 8$ & 0.2 & 2.3 & - & 5.1 & 1.5 & - & - \\
\hline BCL2 & B-Cell Lymphoma 2 & 2.9 & 18.8 & 1.9 & 36.5 & 0.5 & 3.5 & - \\
\hline MYD88 & MYD88 Innate Immune Signal Transduction Adaptor & 2.7 & 17.8 & - & - & 1.2 & 6.6 & - \\
\hline
\end{tabular}

Data for the mutations were obtained from the catalogue of somatic mutations in cancer (COSMIC) database (cancer.sanger.ac.uk/cosmic).

animals, PKC $\beta$ also functions as a Btk-inhibitor in a negative feedback mechanism [33]. Specifically, PKC $\beta$-induced phosphorylation of Btk inhibited the recruitment of the enzyme to the plasma membrane and its subsequent activation. Further experiments using cells from PKC $\beta$-deficient mice demonstrated that PKC $\beta$ regulates the $B C R$-dependent metabolic switch to glycolysis in naive B-cells [34]. In addition, PKC $\beta$ is involved in the BCRinduced activation of NF-KB by phosphorylating CARMA1/CARD11, an important component of the CARMA1/Bcl10/Malt1 (CBM) complex, which functions as an upstream activator of the NF-KB pathway [35]. Finally, PKC $\beta$ isoforms acting downstream of $B C R$ and Orai1 suppress the apoptotic signalling pathway by stimulating the expression of $\mathrm{BCl}-2$ and $\mathrm{BCl}-\mathrm{xL}$ on the one hand [36, 37], and inhibiting the assembly of the death-inducing signalling complex on the other [38].

Earlier reports demonstrated that high expression of PKC $\beta$ was associated with poor survival of DLBCL patients [39-41]. In addition, recurrent mutations in PRKCB (gene encoding PKC $\beta$ ) has been observed in follicular lymphomas [42]. Given its role in different $\mathrm{BCR}$-induced signalling pathways, it is not surprising that knockdown and pharmacological inhibition of $P K C \beta$ suppresses chronic BCR-signalling in the ABC-subtype of DLBCL [43] and cell proliferation [37].

\section{CALPAINS}

Calpains belong to a family of intracellular $\mathrm{Ca}^{+2}$-dependent cysteine proteases that are implicated in a variety of vital biological processes [44]. Activation of calpains downstream of $\mathrm{BCR}$ has been linked to B-cell clonal deletion and establishing the B-cell repertoire [45]. The role of calpains in the pathogenesis of B-cell lymphomas has not been systematically investigated. Studies involving two BL cell lines demonstrated that a calpain inhibitor II (CPI-2) triggers rapid apoptosis [46]. Conversely, BCR activation in WEHI-231 cells, a murine B-cell lymphoma line, induced calpain-dependent cleavage of Caspase-7 leading to apoptosis [47]. In another study, inhibition of calpains decreased the activity of NF-KB1 (p50) homodimers leading to downregulation of the expression of $\mathrm{BCl}-2$, one of the key anti- apoptotic proteins [48]. On the other hand, calpain-dependent cleavage of Bax, a pro-apoptotic member of the Bcl-2 family, may represent a critical initiation step in arsenic sulfide-induced apoptosis of human DLBCL cell lines [49]. In addition to the apoptosis-related signalling network, calpains have been implicated in proteolytic cleavage of Myc thus generating Myc-nick, a truncated protein lacking the C-terminal portion of c-Myc [50]. Myc-nick, that is present in precancerous bone marrow-derived pre-B cells along with full-length $\mathrm{Myc}$ in the $\mathrm{E} \mu-$ myc mouse model of Myc-driven lymphoma [51], was shown to bind microtubules and recruits acetyltransferases to promote a-tubulin acetylation and microtubule stabilization [50]. Finally, calpains were shown to act on Btk [52] and IP3R3 [53], important components of the BCR-dependent signalling network.

\section{CALCINEURIN}

Calcineurin $(\mathrm{CaN})$ is a ubiquitously expressed serine/threonine phosphatase that is activated by calcium and calmodulin, an abundant calcium-sensing cytoplasmic protein [54] (see below). BCR-induced transient release of calcium from internal stores, and sustained influx of extracellular calcium were shown to activate CaN [55]. Early experiments using EBV-positive and EBV-negative lymphoma cell lines suggested that CaN is involved in BCRinduced apoptosis involving activation of caspases-2 and -3 [56]. Subsequent studies demonstrated that in BL cell lines, BCRinduced rapid activation of $\mathrm{CaN}$ resulted in the nuclear translocation of NFATC2, a member of the family of nuclear factor of activated T-cells (NFAT) transcription factors, followed by the increased expression of pro-apoptotic molecule TR3/Nur77 and initiation of the apoptotic programme [57]. The importance of the CaN-NFAT signalling axis in lymphomagenesis is also supported by the observation that $\mathrm{CaN}$-dependent nuclear localisation of NFATC1 was seen in $70 \%$ of BL and $~ 30 \%$ of DLBCL [58]. Although not investigated in B-cell lymphomas, some other CaN substrates have been linked to lymphomagenesis. Increased accumulation of the transcription factor $\mathrm{FOXO}_{3}$ in the nucleus facilitates apoptosis of DLBCL cells treated with ibrutinib, a specific Btk inhibitor [59]. Importantly, an earlier study demonstrated that 
dephosphorylation of $\mathrm{FOXO} 3$ in cells expressing high levels of $\mathrm{CaN}$ is accompanied by the nuclear translocation of FOXO3 [60]. Transcription factor EB (TFEB) has been identified in a genomewide CRISPR screen for genes regulating apilimod-induced cytotoxicity in B-cell non-Hodgkin lymphomas [61]. Apilimod, an antiproliferative compound specifically targeting PIKfyve lipid kinase, induces rapid dephosphorylation of TFEB and protein translocation to the nucleus. While the underlying molecular pathways have not been illustrated in this report, TFEB has been described as a CaN substrate in other cell types [54].

\section{CALCIUM/CALMODULIN KINASES}

$\mathrm{Ca}^{2+} /$ calmodulin (CaM)-dependent protein kinases are activated after they interact with calcium-bound calmodulin (Fig. 2). Whilst several CaM kinases are expressed in normal B cells (https://www. proteinatlas.org/), their role in normal B-cell differentiation remains completely unknown. Reduced mRNA expression of death-associated kinase 1 (DAPK1) due to promoter hypermethylation was observed in $\mathrm{DLBCL}, \mathrm{FL}$ and $\mathrm{cHL}[62,63]$. Furthermore, hypermethylation of the DAPK1 promoter is associated with more aggressive disease and poor outcome in CLL/SLL, DLBCL and FL [64-66]. Experiments involving model B-cell lymphoma cell lines demonstrated CaMKK2-dependent phosphorylation of AMPK may contribute to the induction of autophagy and apoptosis [67]. On the other hand, B-cell activating factor (BAFF) - induced proliferation and survival of normal $B$ cells and $B L$ cell line involved CaMKII-dependent phosphorylation of Akt and activation of the mTOR signalling pathway [68].

\section{THE EPSTEIN-BARR VIRUS AND $\mathrm{CA}^{2+}$ SIGNALLING}

EBV, a gamma human herpesvirus, is an aetiological agent in the pathogenesis of a number of cancers of B-cell origin [69]. In latently infected B cells, the EBV genome can express distinct latency programs [70-72]. The latency III program or the 'growth program' consisting of six EBV nuclear antigens (EBNA-1, -2 , $-3 A,-3 B,-3 C$, and $-L P)$ and three latent membrane proteins (LMP $-1,-2 A$, and $-2 B)$, is expressed in newly infected $B$ cells, and in most cases of EBV-positive DLBCL [73]. Latency II or the 'default program' consisting of EBNA1, LMP1, LMP2A, and LMP2B, is expressed in EBV-infected germinal centre $B$ cells and II is expressed in all cases of EBV-positive cHL [74-76]. Latency I, in which protein expression is limited to only one protein, EBNA1, is characteristic of dividing EBV-infected memory B cells and most cases of EBV-positive BL [70, 71]. Latently infected B cells can also enter the 'Iytic cycle' which ultimately leads to the production of new virions and cell death.

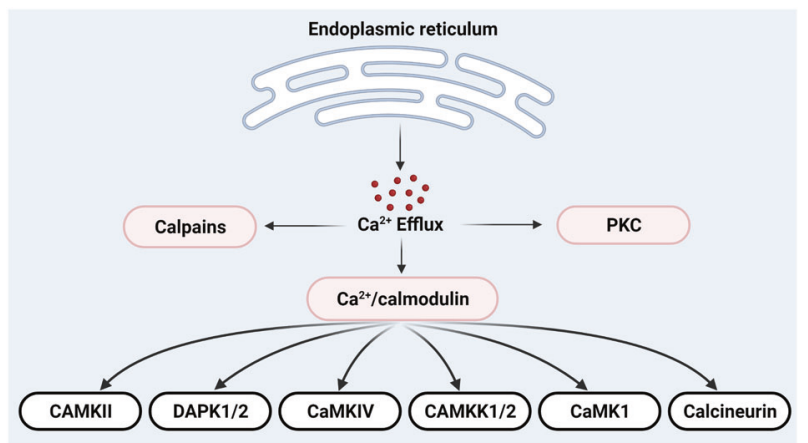

Fig. 2 Intracellular enzymes activated by calcium. Elevations in intracellular $\mathrm{Ca}^{2+}$ result in activation of calmodulin-independent and calmodulin-dependent enzymes.

\section{THE LATENT MEMBRANE PROTEINS OF EBV ARE MAJOR MODULATORS OF CALCIUM-REGULATED SIGNALLING PATHWAYS IN EBV-INFECTED CELLS}

The latent membrane proteins, LMP1 and LMP2A, are expressed in the latency III and latency II programmes, and play a crucial role in calcium-regulated signalling pathways in EBV-infected cells. In turn, calcium signalling has profound effects on EBV life cycle, favouring virus persistence and oncogenesis.

LMP1 is a constitutively active CD40 homologue that can activate a number of signalling pathways, including NF-KB, JAK/ STAT, AP-1, and PI3K/AKT signalling [77-79]. LMP1 expression in Latency II is thought to provide the CD40-like signals required to enable EBV-infected $B$ cells to survive a germinal centre reaction and to subsequently differentiate into plasma cells or memory $B$ cells [80]. LMP1 has been shown to induce many of the features of the aberrant transcriptional programme characteristic of the tumour cells of $\mathrm{CHL}$, including the down-regulation of $\mathrm{BCR}$ signalling components, and the increased expression of antiapoptotic genes such as BCL2 and BFL-1 $[20,81]$. It has been reported that the CaM-dependent protein kinase II (CaMKII), that is activated by LMP1, is crucial for the ability of LMP1 to induce NF$K B$ signalling [82]. CaMKII interacts with interleukin-1 receptor kinase (IRAK1) and this is required for LMP1 induced CaMKII activation. CaMKII directly phosphorylates p65/RelA leading to p65/p50 or p65/p52 mediated transactivation [82]. LMP1 has been shown to increase calcium flux in B cells [83] and it is suggested that LMP1 might activate CaMKII by modulating calcium flux [82]. Specifically, EBV infection of BL cell lines was shown to increase expression of the high $\mathrm{Ca}^{2+}$ affinity SERCA2, and decrease expression of the low $\mathrm{Ca}^{2+}$ affinity, SERCA3, resulting in an increase in the amount of $\mathrm{Ca}^{2+}$ in the lumen of the ER [84]. LMP1 was shown to be responsible for the decrease in SERCA3 expression [83]. LMP1 also activates CaMKIV expression in B cells [84]. Both NFATc1 and NFATC2 induce lytic EBV gene expression when combined with activated CaMKIV [85]. The increased activity of NFAT transcription factors is reported to account for the increased viral lytic cycle activity in B-cells infected with Type 2, compared with Type 1, EBV [85]. In keeping with a crucial role for calcium signalling in regulating the viral lytic cycle, calcineurin inhibitors have been shown to block EBV entry to the lytic cycle following $B C R$ stimulation [86]. LMP2A mimics some of the functions of BCR signalling, for example, by activating ERK/MAPK and PI-3K pathways which is likely to be important for the survival of infected germinal centre B cells [87-89]. At the same time, it was shown that LMP2A can sequester key components of the BCR signalling complex, including Syk and Lyn, thereby partially blocking BCR signalling in infected cells to prevent induction of the virus replicative cycle and thereby maintaining latency $[90,91]$. However, it has subsequently been shown that in the absence of other stimuli, LMP2A can activate the lytic cycle [92]. We and others have shown that while some of the downstream consequences of BCR activation and LMP2A expression do overlap, there are notable differences [93, 94]. Thus, LMP2A concordantly regulates the tyrosine phosphorylation of $\mathrm{PI} 3-$ kinase, Syk, and the $\mathrm{Ca}^{2+}$ initiation complex (comprising BLNK, $\mathrm{BTK}$, and PLC 2 ), resulting in oscillatory $\mathrm{Ca}^{2}+$ fluxes similar to those observed after BCR stimulation [94-96].

\section{$\mathrm{CA}^{2+}$ HOMEOSTASIS AND THERAPEUTIC IMPLICATIONS}

Cytosolic $\mathrm{Ca}^{2+}$ concentration is affected by a number of chemotherapy drugs, some of which are commonly used for treatment of lymphoma patients [97]. Whilst their specific molecular targets and affected $\mathrm{Ca}^{2+}$-dependent pathways have been extensively investigated in the context of nonhaematopoietic cells (normal and malignant) [97-100], there are only a limited number of studies that address the effect of the drugs on calcium homeostasis in B cell lymphomas. 
Humanised anti-CD20 mAbs are routinely used for the treatment of B-cell lymphomas [101]. Targeting CD20 with rituximab (RTX) or Obinutuzumab induces both transient and sustained (Orai1-dependent) influx of $\mathrm{Ca}^{2+}$ to the cytoplasm and activation of Ca-dependent signalling pathways linked to the antibody-induced cell death $[102,103]$. It has been proposed that targeting CD20 with therapeutic antibodies induces CD95(FAS)dependent and CD95-independent apoptosis [102, 103]. Sensitivity to RTX-based chemotherapy was shown to be dependent on the expression levels of Cav1.2, a L-type voltage-gated calcium channel and treatment with a channel agonist markedly increased the sensitivity of DLBCL cell lines to RTX [104].

The R-CHOP therapy (a combination of RTX with cyclophosphamide, doxorubicin, vincristine and prednisolone) is a standard treatment for DLBCL patients. However, $\sim 40 \%$ of the patients treated with R-CHOP are either resistant to the initial treatment or will subsequently relapse [105]. Elevated expression of a number of calcium-binding proteins has been associated with resistance to $\mathrm{R}-\mathrm{CHOP}$ treatment in DLBCL patients. TRPM4 is a calciumdependent monovalent cation channel that transports $\mathrm{K}^{+}$and $\mathrm{Na}^{+}$into cells, which, in turn, regulate intracellular $\mathrm{Ca}^{2+}$ homeostasis [106]. TRPM4 is overexpressed in ABC-DLBCL, and correlates with poorer overall survival of patients treated with R-CHOP [107]. In another study, R-CHOP-resistant DLBCL cell lines expressed high levels of Sorcin [108], a cytosolic multifunctional calcium-binding protein that is also highly expressed in DLBCL samples when compared with normal lymphoid tissues [109].

lbrutinib has proven to be effective in the treatment of both indolent and aggressive B-cell lymphoma [110]. Ibrutinib inhibits BCR-induced calcium flux in normal B cells [111]. Gain of function mutations in the gene encoding PLCY2 [112] are thought to be one of the major factors responsible for resistance to Ibrutinib in patients with MCL [113].

Bortezomib, a reversible proteasome inhibitor is approved for the treatment of relapsed or refractory MCL. The cytotoxic effect of bortezomib on established MCL cell lines and MCL-initiating cells was enhanced in the presence of L-type calcium channels inhibitor potentially through a more potent inhibitory effect on the activation of the NF-KB pathway [114].

\section{FUTURE DIRECTIONS}

There remain significant gaps in our understanding of how $\mathrm{Ca}^{2+}$ dependent signalling contributes to lymphomagenesis. While we need to expand our knowledge of how calcium-dependent enzymes discussed in this review regulates cellular responses in different B-cell lymphomas, a systematic "omics-based" approaches may be necessary to dissect the exact nature of $\mathrm{Ca}^{2+}$-centred signalling networks and how they operate in normal and malignant B-cells. These studies should include other cytoplasmic and secretory proteins whose activity is dependent on calcium (e.g., cyclic nucleotide phosphodiesterase (PDE), adenylyl cyclase, S100, transglutaminase). For example, the role of various plasma membrane calcium pumps and channels in controlling basal intracellular levels of $\mathrm{Ca}^{2+}$ levels requires investigation, as does how changes in the expression of these proteins affect steady-state activities of calcium-dependent enzymes. The results of these experiments may be particularly relevant for lymphoma patients with disrupted calcium haemostasis leading to hypercalcemia, that is associated with shorter progression-free and overall survival $[115,116]$.

Communication between the malignant B-cells and other cell types in the tumour microenvironment is also a critical factor in B-cell lymphomagenesis [117]. Although not investigated in the context of B-cell lymphomas, the contribution of CREB- and NF-KBinduced secretion of cytokines and chemokines downstream of calcium-dependent pathways are well documented in other tumour types. At the post-transcriptional level, calcium-binding proteins in the ER (i.e., calnexin and calreticulin) are well placed to control early steps of the secretory pathway [118]. Finally, calciumdependent signalling pathways are known to control the composition of vesicles secreted by cancerous cells [119], thus affecting the behaviour of other cells in the immediate tumour microenvironment.

Whilst novel therapeutic approaches are beginning to emerge, most lymphoma patients continue to be treated with standard chemotherapy with or without CD20-targeting antibodies. A better understanding of how commonly used chemotherapy drugs affect the expression and function of key players within calcium-centred signalling networks may provide a solid basis for further optimisation of the current treatment protocols and the development of new therapeutic strategies.

\section{REFERENCES}

1. Seifert M, Scholtysik R, Kuppers R. Origin and Pathogenesis of B Cell Lymphomas. Methods Mol Biol. 2019;1956:1-33.

2. MacLennan IC. Germinal centers. Annu Rev Immunol. 1994;12:117-39.

3. Hobeika E, Nielsen PJ, Medgyesi D. Signaling mechanisms regulating B-lymphocyte activation and tolerance. J Mol Med (Berl). 2015;93:143-58.

4. Sato S, Steeber DA, Tedder TF. The CD19 signal transduction molecule is a response regulator of B-lymphocyte differentiation. Proc Natl Acad Sci USA. 1995;92:11558-62.

5. Chen J, McLean PA, Neel BG, Okunade G, Shull GE, Wortis HH. CD22 attenuates calcium signaling by potentiating plasma membrane calcium-ATPase activity. Nat Immunol. 2004;5:651-7.

6. Polouliakh N, Nock R, Nielsen F, Kitano H. G-protein coupled receptor signaling architecture of mammalian immune cells. PLoS ONE. 2009;4:e4189.

7. Montresor A, Toffali L, Rigo A, Ferrarini I, Vinante F, Laudanna C. CXCR4- and BCRtriggered integrin activation in B-cell chronic lymphocytic leukemia cells depends on JAK2-activated Bruton's tyrosine kinase. Oncotarget. 2018;9:35123-40.

8. Shirakawa AK, Liao F, Zhang HH, Hedrick MN, Singh SP, Wu D, et al. Pathwayselective suppression of chemokine receptor signaling in B cells by LPS through downregulation of PLC-beta2. Cell Mol Immunol. 2010;7:428-39.

9. Taylor CW. Regulation of IP3 receptors by cyclic AMP. Cell Calcium. 2017:63:48-52.

10. Mahtani T, Treanor B. Beyond the CRAC: Diversification of ion signaling in B cells. Immunol Rev. 2019;291:104-22.

11. Numaga $T$, Nishida $M$, Kiyonaka $S$, Kato $K$, Katano $M$, Mori $E$, et al. $\mathrm{Ca}^{2+}$ influx and protein scaffolding via TRPC3 sustain PKCbeta and ERK activation in B cells. J Cell Sci. 2010;123:927-38.

12. Chuang SS, Ye H, Du MQ, Lu CL, Dogan A, Hsieh PP, et al. Histopathology and immunohistochemistry in distinguishing Burkitt lymphoma from diffuse large B-cell lymphoma with very high proliferation index and with or without a starrysky pattern: a comparative study with EBER and FISH. Am J Clin Pathol. 2007;128:558-64.

13. Davis RE, Ngo VN, Lenz G, Tolar P, Young RM, Romesser PB, et al. Chronic active B-cell-receptor signalling in diffuse large B-cell lymphoma. Nature. 2010;463:88-92.

14. Young RM, Wu T, Schmitz R, Dawood M, Xiao W, Phelan JD, et al. Survival of human lymphoma cells requires B-cell receptor engagement by self-antigens. Proc Natl Acad Sci USA. 2015;112:13447-54.

15. Chen L, Monti S, Juszczynski P, Daley J, Chen W, Witzig TE, et al. SYK-dependent tonic B-cell receptor signaling is a rational treatment target in diffuse large B-cell lymphoma. Blood. 2008;111:2230-7.

16. Havranek O, Xu J, Kohrer S, Wang Z, Becker L, Comer JM, et al. Tonic B-cell receptor signaling in diffuse large B-cell lymphoma. Blood. 2017;130:995-1006.

17. Ten Hacken E, Guieze R, Wu CJ. SnapShot: Chronic lymphocytic leukemia. Cancer Cell. 2017;32:716. e711.

18. Weniger MA, Kuppers R. Molecular biology of Hodgkin lymphoma. Leukemia. 2021;35:968-81.

19. Portis T, Dyck P, Longnecker R. Epstein-Barr Virus (EBV) LMP2A induces alterations in gene transcription similar to those observed in Reed-Sternberg cells of Hodgkin lymphoma. Blood. 2003;102:4166-78.

20. Vockerodt M, Morgan SL, Kuo M, Wei W, Chukwuma MB, Arrand JR, et al. The Epstein-Barr virus oncoprotein, latent membrane protein-1, reprograms germinal centre B cells towards a Hodgkin's Reed-Sternberg-like phenotype. J Pathol. 2008;216:83-92.

21. Linley A, Krysov S, Ponzoni M, Johnson PW, Packham G, Stevenson FK. Lectin binding to surface Ig variable regions provides a universal persistent activating signal for follicular lymphoma cells. Blood. 2015;126:1902-10. 
22. Latour S, Mahouche I, Cherrier F, Azzi-Martin L, Velasco V, Soubeyran P et al. Calcium Independent Effect of Orai1 and STIM1 in Non-Hodgkin B Cell Lymphoma Dissemination. Cancers (Basel) 2018;10. https://doi.org/10.3390/ cancers10110402.

23. Kim J, Kim DW, Chang W, Choe J, Kim J, Park CS, et al. Wnt5a is secreted by follicular dendritic cells to protect germinal center B cells via Wnt/Ca ${ }^{2}+$ /NFAT/ NF-kappaB-B cell lymphoma 6 signaling. J Immunol. 2012;188:182-9.

24. Nakashima $M$, Watanabe $M$, Uchimaru $K$, Horie $R$. Trogocytosis of ligandreceptor complex and its intracellular transport in CD30 signalling. Biol Cell. 2018;110:109-24.

25. Schain F, Tryselius Y, Sjoberg J, Porwit A, Backman L, Malec M, et al. Evidence for a pathophysiological role of cysteinyl leukotrienes in classical Hodgkin lymphoma. Int J Cancer. 2008;123:2285-93.

26. Schain F, Schain D, Mahshid Y, Liu C, Porwit A, Xu D, et al. Differential expression of cysteinyl leukotriene receptor 1 and 15-lipoxygenase-1 in non-Hodgkin lymphomas. Clin Lymphoma Myeloma. 2008;8:340-7.

27. Wist M, Meier L, Gutman O, Haas J, Endres S, Zhou Y, et al. Noncatalytic Bruton's tyrosine kinase activates PLCgamma2 variants mediating ibrutinib resistance in human chronic lymphocytic leukemia cells. J Biol Chem. 2020;295:5717-36.

28. Singh K, Briggs JM. Functional Implications of the spectrum of BCL2 mutations in Lymphoma. Mutat Res Rev Mutat Res. 2016;769:1-18.

29. Saijo K, Mecklenbrauker I, Schmedt C, Tarakhovsky A. B cell immunity regulated by the protein kinase C family. Ann N. Y Acad Sci. 2003;987:125-34.

30. Pfeifhofer C, Gruber T, Letschka T, Thuille N, Lutz-Nicoladoni C, Hermann-Kleiter $\mathrm{N}$, et al. Defective IgG2a/2b class switching in PKC alpha-/- mice. J Immunol. 2006;176:6004-11.

31. Azar AA, Michie AM, Tarafdar A, Malik N, Menon GK, Till KJ, et al. A novel transgenic mouse strain expressing PKCbetall demonstrates expansion of B1 and marginal zone B cell populations. Sci Rep. 2020;10:13156.

32. Leitges M, Schmedt C, Guinamard R, Davoust J, Schaal S, Stabel S, et al. Immunodeficiency in protein kinase cbeta-deficient mice. Science. 1996;273:788-91.

33. Kang SW, Wahl MI, Chu J, Kitaura J, Kawakami Y, Kato RM, et al. PKCbeta modulates antigen receptor signaling via regulation of Btk membrane localization. EMBO J. 2001;20:5692-702.

34. Blair D, Dufort FJ, Chiles TC. Protein kinase Cbeta is critical for the metabolic switch to glycolysis following B-cell antigen receptor engagement. Biochem J. 2012;448:165-9.

35. Sommer K, Guo B, Pomerantz JL, Bandaranayake AD, Moreno-Garcia ME, Ovechkina $\mathrm{YL}$, et al. Phosphorylation of the CARMA1 linker controls NF-kappaB activation. Immunity. 2005;23:561-74.

36. Venkataraman C, Chen XC, Na S, Lee L, Neote K, Tan SL. Selective role of PKCbeta enzymatic function in regulating cell survival mediated by $B$ cell antigen receptor cross-linking. Immunol Lett. 2006;105:83-9.

37. Su T, Guo B, Kawakami Y, Sommer K, Chae K, Humphries LA, et al. PKC-beta controls I kappa $B$ kinase lipid raft recruitment and activation in response to $B C R$ signaling. Nat Immunol. 2002;3:780-6.

38. Khadra N, Bresson-Bepoldin L, Penna A, Chaigne-Delalande B, Segui B, Levade T, et al. CD95 triggers Orai1-mediated localized $\mathrm{Ca}^{2+}$ entry, regulates recruitment of protein kinase $C$ (PKC) beta2, and prevents death-inducing signaling complex formation. Proc Natl Acad Sci USA. 2011;108:19072-7.

39. Li S, Phong M, Lahn M, Brail L, Sutton S, Lin BK, et al. Retrospective analysis of protein kinase C-beta (PKC-beta) expression in lymphoid malignancies and its association with survival in diffuse large B-cell lymphomas. Biol Direct. 2007;2:8.

40. Espinosa I, Briones J, Bordes R, Brunet S, Martino R, Sureda A, et al. Membrane PKC-beta 2 protein expression predicts for poor response to chemotherapy and survival in patients with diffuse large B-cell lymphoma. Ann Hematol. 2006;85:597-603

41. Hans CP, Weisenburger DD, Greiner TC, Chan WC, Aoun P, Cochran GT, et al. Expression of PKC-beta or cyclin D2 predicts for inferior survival in diffuse large B-cell lymphoma. Mod Pathol. 2005;18:1377-84.

42. Krysiak K, Gomez F, White BS, Matlock M, Miller CA, Trani L, et al. Recurrent somatic mutations affecting $B$-cell receptor signaling pathway genes in follicular lymphoma. Blood. 2017;129:473-83.

43. Naylor TL, Tang H, Ratsch BA, Enns A, Loo A, Chen L, et al. Protein kinase C inhibitor sotrastaurin selectively inhibits the growth of CD79 mutant diffuse large B-cell lymphomas. Cancer Res. 2011;71:2643-53.

44. Chen Y, Su Z, Liu F. Effects of functionally diverse calpain system on immune cells. Immunol Res. 2021;69:8-17.

45. Ruiz-Vela A, Serrano F, Gonzalez MA, Abad JL, Bernad A, Maki M, et al. Transplanted long-term cultured pre-BI cells expressing calpastatin are resistant to $B$ cell receptor-induced apoptosis. J Exp Med. 2001;194:247-54.

46. Zhu DM, Uckun FM. Calpain inhibitor II induces caspase-dependent apoptosis in human acute lymphoblastic leukemia and non-Hodgkin's lymphoma cells as well as some solid tumor cells. Clin Cancer Res. 2000;6:2456-63.
47. Ruiz-Vela A, Gonzalez de Buitrago G, Martinez AC. Implication of calpain in caspase activation during B cell clonal deletion. EMBO J. 1999;18:4988-98.

48. Kurland JF, Kodym R, Story MD, Spurgers KB, McDonnell TJ, Meyn RE. NFkappaB1 (p50) homodimers contribute to transcription of the bcl-2 oncogene. J Biol Chem. 2001;276:45380-6.

49. Wang L, Liu X, Li X, Lv X, Lu K, Chen N, et al. Arsenic disulfide induces apoptosis of human diffuse large $B$ cell lymphoma cells involving Bax cleavage. Oncol Rep. 2013;30:2427-34.

50. Conacci-Sorrell M, Eisenman RN. Post-translational control of Myc function during differentiation. Cell Cycle. 2011;10:604-10.

51. Conacci-Sorrell M, Ngouenet C, Anderson S, Brabletz T, Eisenman RN. Stressinduced cleavage of Myc promotes cancer cell survival. Genes Dev. 2014;28:689-707.

52. Mukhopadhyay S, Ramars AS, Ochs HD, Dash D. Bruton's tyrosine kinase is a substrate of calpain in human platelets. FEBS Lett. 2001;505:37-41.

53. Diaz F, Bourguignon LY. Selective down-regulation of IP(3)receptor subtypes by caspases and calpain during TNF alpha -induced apoptosis of human T-lymphoma cells. Cell Calcium. 2000;27:315-28.

54. Creamer TP. Calcineurin. Cell Commun Signal. 2020;18:137.

55. Medyouf $\mathrm{H}$, Ghysdael J. The calcineurin/NFAT signaling pathway: a novel therapeutic target in leukemia and solid tumors. Cell Cycle. 2008;7:297-303.

56. Chen W, Wang HG, Srinivasula SM, Alnemri ES, Cooper NR. B cell apoptosis triggered by antigen receptor ligation proceeds via a novel caspase-dependent pathway. J Immunol. 1999;163:2483-91.

57. Kondo E, Harashima A, Takabatake T, Takahashi H, Matsuo Y, Yoshino T, et al. NF-ATc2 induces apoptosis in Burkitt's lymphoma cells through signaling via the B cell antigen receptor. Eur J Immunol. 2003;33:1-11.

58. Marafioti $T$, Pozzobon $M$, Hansmann $M L$, Ventura $R$, Pileri $S A$, Roberton $H$, et al. The NFATc1 transcription factor is widely expressed in white cells and translocates from the cytoplasm to the nucleus in a subset of human lymphomas. $\mathrm{Br} J$ Haematol. 2005;128:333-42.

59. Kapoor I, Li Y, Sharma A, Zhu H, Bodo J, Xu W, et al. Resistance to BTK inhibition by ibrutinib can be overcome by preventing FOXO3a nuclear export and $\mathrm{PI} 3 \mathrm{~K} /$ AKT activation in B-cell lymphoid malignancies. Cell Death Dis. 2019;10:924.

60. Tao L, Xie Q, Ding YH, Li ST, Peng S, Zhang YP, et al. CAMKII and calcineurin regulate the lifespan of Caenorhabditis elegans through the FOXO transcription factor DAF-16. Elife. 2013;2:e00518.

61. Gayle S, Landrette S, Beeharry N, Conrad C, Hernandez M, Beckett P, et al. Identification of apilimod as a first-in-class PIKfyve kinase inhibitor for treatment of B-cell non-Hodgkin lymphoma. Blood. 2017;129:1768-78.

62. Frazzi $R$, Zanetti E, Pistoni M, Tamagnini I, Valli $R$, Braglia $L$, et al. Methylation changes of SIRT1, KLF4, DAPK1 and SPG20 in B-lymphocytes derived from follicular and diffuse large B-cell lymphoma. Leuk Res. 2017;57:89-96.

63. Dhiab MB, Ziadi S, Mestiri S, Gacem RB, Ksiaa F, Trimeche M. DNA methylation patterns in EBV-positive and EBV-negative Hodgkin lymphomas. Cell Oncol (Dordr). 2015;38:453-62.

64. Kristensen LS, Asmar F, Dimopoulos K, Nygaard MK, Aslan D, Hansen JW, et al. Hypermethylation of DAPK1 is an independent prognostic factor predicting survival in diffuse large B-cell lymphoma. Oncotarget. 2014;5:9798-810.

65. Giachelia M, Bozzoli V, D'Alo F, Tisi MC, Massini G, Maiolo E, et al. Quantification of DAPK1 promoter methylation in bone marrow and peripheral blood as a follicular lymphoma biomarker. J Mol Diagn. 2014;16:467-76.

66. Raval A, Tanner SM, Byrd JC, Angerman EB, Perko JD, Chen SS, et al. Downregulation of death-associated protein kinase 1 (DAPK1) in chronic lymphocytic leukemia. Cell. 2007;129:879-90.

67. Cheng C, Wang T, Song Z, Peng L, Gao M, Hermine O, et al. Induction of autophagy and autophagy-dependent apoptosis in diffuse large B-cell lymphoma by a new antimalarial artemisinin derivative, SM1044. Cancer Med. 2018;7:380-96

68. Dong X, Qin J, Ma J, Zeng Q, Zhang H, Zhang R, et al. BAFF inhibits autophagy promoting cell proliferation and survival by activating $\mathrm{Ca}(2+)$-CaMKII-dependent Akt/mTOR signaling pathway in normal and neoplastic B-lymphoid cells. Cell Signal. 2019;53:68-79.

69. Young LS, Yap LF, Murray PG. Epstein-Barr virus: more than 50 years old and still providing surprises. Nat Rev Cancer. 2016;16:789-802.

70. Rowe M, Rowe DT, Gregory CD, Young LS, Farrell PJ, Rupani H, et al. Differences in $B$ cell growth phenotype reflect novel patterns of Epstein-Barr virus latent gene expression in Burkitt's lymphoma cells. EMBO J. 1987;6:2743-51.

71. Rowe M, Lear AL, Croom-Carter D, Davies AH, Rickinson AB. Three pathways of Epstein-Barr virus gene activation from EBNA1-positive latency in B lymphocytes. J Virol. 1992;66:122-31.

72. Pfeffer S, Zavolan M, Grasser FA, Chien M, Russo JJ, Ju J, et al. Identification of virus-encoded microRNAs. Science. 2004;304:734-6.

73. Ok CY, Papathomas TG, Medeiros LJ, Young KH. EBV-positive diffuse large B-cell lymphoma of the elderly. Blood. 2013;122:328-40. 
74. Pallesen G, Hamilton-Dutoit SJ, Rowe M, Young LS. Expression of Epstein-Barr virus latent gene products in tumour cells of Hodgkin's disease. Lancet. 1991;337:320-2.

75. Murray PG, Young LS, Rowe M, Crocker J. Immunohistochemical demonstration of the Epstein-Barr virus-encoded latent membrane protein in paraffin sections of Hodgkin's disease. J Pathol. 1992;166:1-5.

76. Deacon EM, Pallesen G, Niedobitek G, Crocker J, Brooks L, Rickinson AB, et al. Epstein-Barr virus and Hodgkin's disease: transcriptional analysis of virus latency in the malignant cells. J Exp Med. 1993;177:339-49.

77. Floettmann JE, Rowe M. Epstein-Barr virus latent membrane protein-1 (LMP1) C-terminus activation region 2 (CTAR2) maps to the far C-terminus and requires oligomerisation for NF-kappaB activation. Oncogene. 1997;15:1851-8.

78. Shair KH, Bendt KM, Edwards RH, Bedford EC, Nielsen JN, Raab-Traub N. EBV latent membrane protein 1 activates Akt, NFkappaB, and Stat3 in B cell lymphomas. PLoS Pathog. 2007;3:e166.

79. Zhang L, Hong K, Zhang J, Pagano JS. Multiple signal transducers and activators of transcription are induced by EBV LMP-1. Virology. 2004;323:141-52.

80. Babcock GJ, Hochberg D, Thorley-Lawson AD. The expression pattern of EpsteinBarr virus latent genes in vivo is dependent upon the differentiation stage of the infected B cell. Immunity. 2000;13:497-506.

81. Henderson S, Rowe M, Gregory C, Croom-Carter D, Wang F, Longnecker R, et al. Induction of bcl-2 expression by Epstein-Barr virus latent membrane protein 1 protects infected B cells from programmed cell death. Cell. 1991;65:1107-15.

82. Kim JE, Kim SY, Lim SY, Kieff E, Song YJ. Role of $\mathrm{Ca}^{2}+$ /calmodulin-dependent kinase II-IRAK1 interaction in LMP1-induced NF-kappaB activation. Mol Cell Biol. 2014;34:325-34.

83. Dellis O, Arbabian A, Papp B, Rowe M, Joab I, Chomienne C. Epstein-Barr virus latent membrane protein 1 increases calcium influx through store-operated channels in B lymphoid cells. J Biol Chem. 2011;286:18583-92.

84. Jones RJ, Seaman WT, Feng WH, Barlow E, Dickerson S, Delecluse HJ, et al. Roles of lytic viral infection and IL-6 in early versus late passage lymphoblastoid cell lines and EBV-associated lymphoproliferative disease. Int $\mathrm{J}$ Cancer. 2007;121:1274-81.

85. Romero-Masters JC, Huebner SM, Ohashi M, Bristol JA, Benner BE, Barlow EA, et al. B cells infected with Type 2 Epstein-Barr virus (EBV) have increased NFATc1/NFATC2 activity and enhanced lytic gene expression in comparison to Type 1 EBV infection. PLoS Pathog. 2020;16:e1008365.

86. Kosowicz JG, Lee J, Peiffer B, Guo Z, Chen J, Liao G et al. Drug modulators of $b$ cell signaling pathways and Epstein-Barr virus lytic activation. J Virol. 2017; 91. https://doi.org/10.1128/JVI.00747-17.

87. Fruehling S, Swart R, Dolwick KM, Kremmer E, Longnecker R. Tyrosine 112 of latent membrane protein $2 \mathrm{~A}$ is essential for protein tyrosine kinase loading and regulation of Epstein-Barr virus latency. J Virol. 1998;72:7796-806.

88. Merchant M, Longnecker R. LMP2A survival and developmental signals are transmitted through Btk-dependent and Btk-independent pathways. Virology. 2001;291:46-54.

89. Portis T, Longnecker R. Epstein-Barr virus (EBV) LMP2A mediates B-lymphocyte survival through constitutive activation of the Ras/PI3K/Akt pathway. Oncogene. 2004;23:8619-28.

90. Miller $\mathrm{CL}$, Lee $\mathrm{JH}$, Kieff $\mathrm{E}$, Longnecker R. An integral membrane protein (LMP2) blocks reactivation of Epstein-Barr virus from latency following surface immunoglobulin crosslinking. Proc Natl Acad Sci USA. 1994;91:772-6.

91. Miller CL, Burkhardt AL, Lee JH, Stealey B, Longnecker R, Bolen JB, et al. Integra membrane protein 2 of Epstein-Barr virus regulates reactivation from latency through dominant negative effects on protein-tyrosine kinases. Immunity. 1995;2:155-66

92. Schaadt E, Baier B, Mautner J, Bornkamm GW, Adler B. Epstein-Barr virus latent membrane protein $2 \mathrm{~A}$ mimics $\mathrm{B}$-cell receptor-dependent virus reactivation. J Gen Virol. 2005;86:551-9.

93. Vockerodt M, Wei W, Nagy E, Prouzova Z, Schrader A, Kube D, et al. Suppression of the LMP2A target gene, EGR-1, protects Hodgkin's lymphoma cells from entry to the EBV lytic cycle. J Pathol. 2013;230:399-409.

94. Fish K, Comoglio F, Shaffer AL 3rd, Ji Y, Pan KT, Scheich S, et al. Rewiring of B cell receptor signaling by Epstein-Barr virus LMP2A. Proc Natl Acad Sci USA. 2020;117:26318-27.

95. Engelke $\mathrm{M}$, Engels $\mathrm{N}$, Dittmann $\mathrm{K}$, Stork $\mathrm{B}$, Wienands J. $\mathrm{Ca}(2+)$ signaling in antigen receptor-activated B lymphocytes. Immunol Rev. 2007;218:235-46.

96. Oellerich T, Bremes V, Neumann K, Bohnenberger H, Dittmann K, Hsiao HH, et al. The B-cell antigen receptor signals through a preformed transducer module of SLP65 and CIN85. EMBO J. 2011;30:3620-34.

97. Varghese E, Samuel SM, Sadiq Z, Kubatka P, Liskova A, Benacka J et al. Anticancer agents in proliferation and cell death: The calcium connection. Int J Mol Sci. 2019;20. https://doi.org/10.3390/ijms20123017.
98. Kim CW, Choi KC. Effects of anticancer drugs on the cardiac mitochondrial toxicity and their underlying mechanisms for novel cardiac protective strategies. Life Sci. 2021;277:119607.

99. Varela-Lopez A, Battino M, Navarro-Hortal MD, Giampieri F, Forbes-Hernandez TY, Romero-Marquez JM, et al. An update on the mechanisms related to cell death and toxicity of doxorubicin and the protective role of nutrients. Food Chem Toxicol. 2019;134:110834.

100. He X, Dou A, Feng S, Roman-Rivera A, Hawkins C, Lawley L, et al. Cyclosporine enhances the sensitivity to lenalidomide in MDS/AML in vitro. Exp Hematol. 2020;86:21-7. e22

101. Marshall MJE, Stopforth RJ, Cragg MS. Therapeutic antibodies: What have we learnt from targeting $\mathrm{CD} 20$ and where are we going? Front Immunol. 2017;8:1245.

102. Latour S, Zanese M, Le Morvan V, Vacher AM, Menard N, Bijou F et al. Role of calcium signaling in GA101-induced cell death in malignant human B Cells. Cancers (Basel) 2019;11. https://doi.org/10.3390/cancers11030291.

103. Vacher $P$, Vacher AM, Pineau R, Latour S, Soubeyran I, Pangault $C$, et al. Localized store-operated calcium influx represses CD95-dependent apoptotic effects of rituximab in non-hodgkin B lymphomas. J Immunol. 2015;195:2207-15.

104. Zhang JY, Zhang PP, Zhou WP, Yu JY, Yao ZH, Chu JF, et al. L-Type Cav 1.2 calcium channel-alpha- $1 \mathrm{C}$ regulates response to rituximab in diffuse large $\mathrm{B}$-Cell lymphoma. Clin Cancer Res. 2019;25:4168-78.

105. Wang L, Li LR. R-CHOP resistance in diffuse large B-cell lymphoma: biological and molecular mechanisms. Chin Med J (Engl). 2020;134:253-60.

106. Borgstrom A, Peinelt C, Stoklosa P TRPM4 in cancer-A new potential drug target. Biomolecules 2021;11. https://doi.org/10.3390/biom11020229.

107. Loo SK, Ch'ng ES, Md Salleh MS, Banham AH, Pedersen LM, Moller MB, et al. TRPM4 expression is associated with activated $B$ cell subtype and poor survival in diffuse large B cell lymphoma. Histopathology. 2017;71:98-111.

108. Mao J, Ling F, Gislaine Pires Sanches J, Yu X, Wei Y, Zhang J. The potential mechanism of action of Sorcin and its interacting proteins. Clin Chim Acta. 2020;510:741-5.

109. Maxwell SA, Cherry EM, Bayless KJ. Akt, 14-3-3zeta, and vimentin mediate a drug-resistant invasive phenotype in diffuse large B-cell lymphoma. Leuk Lymphoma. 2011;52:849-64.

110. Xue C, Wang $X$, Zhang $L, Q u$ Q, Zhang Q, Jiang Y. Ibrutinib in B-cell lymphoma: single fighter might be enough? Cancer Cell Int. 2020;20:467.

111. de Porto AP, Liu Z, de Beer R, Florquin S, de Boer OJ, Hendriks RW, et al. Btk inhibitor ibrutinib reduces inflammatory myeloid cell responses in the lung during murine pneumococcal pneumonia. Mol Med. 2019;25:3.

112. Consortium APG. AACR project GENIE: Powering precision medicine through an international consortium. Cancer Disco. 2017;7:818-31.

113. Ondrisova $L, M r a z M$. Genetic and non-genetic mechanisms of resistance to $B C R$ signaling inhibitors in B Cell malignancies. Front Oncol. 2020;10:591577.

114. Jung HJ, Chen Z, Wang M, Fayad L, Romaguera J, Kwak LW, et al. Calcium blockers decrease the bortezomib resistance in mantle cell lymphoma via manipulation of tissue transglutaminase activities. Blood. 2012;119:2568-78.

115. Gauchy AC, Kanagaratnam L, Quinquenel A, Gaillard B, Rodier C, Godet S, et al. Hypercalcemia at diagnosis of diffuse large B-cell lymphoma is not uncommon and is associated with high-risk features and a short diagnosis-to-treatment interval. Hematol Oncol. 2020;38:326-33.

116. Vallet N, Ertault M, Delaye JB, Chalopin T, Villate A, Drieu La Rochelle L, et al. Hypercalcemia is associated with a poor prognosis in lymphoma a retrospective monocentric matched-control study and extensive review of published reported cases. Ann Hematol. 2020;99:229-39.

117. Scott DW, Gascoyne RD. The tumour microenvironment in B cell lymphomas. Nat Rev Cancer. 2014;14:517-34.

118. Sicari D, Igbaria A, Chevet E. Control of protein homeostasis in the early secretory pathway: Current status and challenges. Cells. 2019;8. https://doi.org/ 10.3390/cells8111347.

119. Taylor J, Azimi I, Monteith G, Bebawy M. $\mathrm{Ca}(2+)$ mediates extracellular vesicle biogenesis through alternate pathways in malignancy. J Extracell Vesicles. 2020;9:1734326.

\section{ACKNOWLEDGEMENTS}

The work was funded by the Seeding Discovery award from the Wellcome Trust [202708/Z/16/A] and a European Regional Development Fund Project (ENOCH: CZ.02.1.01/0.0/0.0/16_019/0000868). Figures were created with BioRender.com.

\section{AUTHOR CONTRIBUTIONS}

FB and PGM conceived the idea and were responsible for writing. EF designed illustrative material and contributed to organising the structure of the article. 
6328

\section{COMPETING INTERESTS}

The authors declare no competing interests.

\section{ADDITIONAL INFORMATION}

Correspondence and requests for materials should be addressed to Fedor Berditchevski or Paul G. Murray.

Reprints and permission information is available at http://www.nature.com/ reprints

Publisher's note Springer Nature remains neutral with regard to jurisdictional claims in published maps and institutional affiliations.
Open Access This article is licensed under a Creative Commons Attribution 4.0 International License, which permits use, sharing, adaptation, distribution and reproduction in any medium or format, as long as you give appropriate credit to the original author(s) and the source, provide a link to the Creative Commons license, and indicate if changes were made. The images or other third party material in this article are included in the article's Creative Commons license, unless indicated otherwise in a credit line to the material. If material is not included in the article's Creative Commons license and your intended use is not permitted by statutory regulation or exceeds the permitted use, you will need to obtain permission directly from the copyright holder. To view a copy of this license, visit http://creativecommons. org/licenses/by/4.0/.

(c) The Author(s) 2021 